\title{
Control of Wheat Fusarium Head Blight by Heat-Stable Antifungal Factor (HSAF) from Lysobacter enzymogenes
}

\author{
Yangyang Zhao, ${ }^{1}$ Chao Cheng, ${ }^{2,3}$ Tianping Jiang, ${ }^{1,4}$ Huiyong Xu, ${ }^{1}$ Yun Chen, ${ }^{5}$ Zhonghua Ma, ${ }^{5}$ Guoliang Qian, \\ and Fengquan Liu ${ }^{1,6, \dagger}$ \\ ${ }^{1}$ Institute of Plant Protection, Jiangsu Academy of Agricultural Sciences, Jiangsu Key Laboratory for Food Quality and Safety, \\ State Key Laboratory Cultivation Base of Ministry of Science and Technology, Nanjing 210014, P.R. China; ${ }^{2}$ College of Plant \\ Protection, Nanjing Agricultural University, Nanjing 210095, P.R. China; ${ }^{3}$ Key Laboratory of Integrated Management of Crop \\ Diseases and Pests (Nanjing Agricultural University), Ministry of Education, Nanjing 210095, P.R. China; ${ }^{4}$ College of Horticul- \\ ture and Plant Protection, Yangzhou University, Yangzhou 225009, P. R. China; ${ }^{5}$ State Key Laboratory of Rice Biology, Institute \\ of Biotechnology, Zhejiang University, Hangzhou 310058, P. R. China; and ${ }^{6}$ Institute of Life Sciences, Jiangsu University, Zhen- \\ jiang 212013, P. R. China
}

\begin{abstract}
Heat-stable antifungal factor (HSAF), which belongs to the polycyclic tetramate macrolactam family, was isolated from Lysobacter enzymogenes fermentations and exhibited inhibitory activities against a wide range of fungal pathogens. In this study, the antifungal activity of HSAF against Fusarium graminearum in vitro and in vivo was investigated. A total of $50 \%$ of mycelial growth of $F$. graminearum was suppressed with $4.1 \mu \mathrm{g} / \mathrm{ml}$ of HSAF (EC ${ }_{50}$ value). HSAF treatment resulted in abnormal morphology of the hyphae, such as curling, apical swelling, and
\end{abstract}

Fusarium head blight (FHB), primarily caused by Fusarium graminearum, is a devastating fungal disease observed worldwide that results in yield and quality losses of wheat and other small grains (Dean et al. 2012). In addition to the yield and quality reduction, the notable problem is mycotoxin contamination of grains, primarily with deoxynivalenol (DON), which is toxic to animals and humans (EFSA Panel on Contaminants in the Food Chain et al. 2017; Katika et al. 2014; Pestka 2010; Sobrova et al. 2010). Different strategies have been applied to control FHB infection, including agronomic practices, resistant cultivars, chemical fungicides, and biological control (Dweba et al. 2017; Wegulo et al. 2015). Of these strategies, chemical fungicide control is the most widely used, particularly the demethylation inhibitors (DMIs, e.g., tebuconazole, prothioconazole, and metconazole) and benzimidazole fungicides (MBC, e.g., carbendazim) (Chen and Zhou 2009; McMullen et al. 2012). However, since the discovery of carbendazim-resistant isolates in China (Chen and Zhou 2009) and tebuconazole-resistant isolates in the United States (Spolti et al. 2014), the need to develop fungicides with new mechanisms of action is urgent.

In the search for new fungicide leads, secondary metabolite heatstable antifungal factor (HSAF, dihydromaltophilin) belonging to the polycyclic tetramate macrolactams (Fig. 1) was isolated from Lysobacter enzymogenes $\mathrm{C} 3$ and $\mathrm{OH} 11$ fermentations (Lou et al. 2011; $\mathrm{Yu}$ et al. 2007). L. enzymogenes belongs to the Xanthomonadaceae family and is emerging as an effective bacterial biocontrol agent

${ }^{\dagger}$ Corresponding author: F. Q. Liu; fqliu20011@sina.com

Y. Y. Zhao and C. Cheng contributed equally to this work.

Funding: This research was financially supported by the National Key R\&D Program of China (2017YFD0201100).

The author(s) declare no conflict of interest.

Accepted for publication 22 January 2019.

() 2019 The American Phytopathological Society against fungal plant diseases (Folman et al. 2003, 2004; Jochum et al. 2006; Qian et al. 2009; Zhang and Yuen 1999). L. enzymogenes strain $\mathrm{OH} 11$ was isolated from the rhizosphere of green pepper and shared $99 \%$ genetic similarity with strain C3 according to phylogenetic analysis (Qian et al. 2009). The unusual hybrid polyketide synthase/nonribosomal peptide synthetase biosynthetic mechanism and regulatory pathways of HSAF have been extensively studied in L. enzymogenes strain OH11 (Lou et al. 2011; Qian et al. 2013; $\mathrm{Su}$ et al. 2017; $\mathrm{Xu}$ et al. 2018). HSAF exhibits potent inhibitory activities against a wide range of filamentous fungal pathogens by disrupting sphingolipid biosynthesis, which induces cell wall thickening and depolarizes hyphal growth of Aspergillus nidulans ( $\mathrm{Li}$ et al. 2006, 2009). Furthermore, HSAF is also efficient in killing the nonfilamentous fungus of Candida albicans by inducing apoptosis through reactive oxygen species accumulation (Ding et al. 2016). Collectively, the unique characteristics described above make HSAF particularly attractive as a potential chemical pesticide, particularly for controlling fungal pathogens that are resistant to currently applied pesticides. However, there was no specific report about the mode action of HSAF on $F$. graminearum and its control effect in wheat FHB.

In this study, we investigated the inhibitory activity of HSAF against $F$. graminearum in vitro and assessed the potential of HSAF for controlling FHB in the field. The antifungal mechanism of HSAF against $F$. graminearum was also explored.

\section{Materials and Methods}

Strains and growth conditions. L. enzymogenes strain $\mathrm{OH} 11$ (CGMCC no. 1978) was isolated from the rhizosphere of green pepper in Jiangsu Academy of Agricultural Sciences of China (Qian et al. 2009). OH11 was grown in Luria broth (LB) medium (10 g of tryptone, $5 \mathrm{~g}$ of yeast extract, and $10 \mathrm{~g}$ of $\mathrm{NaCl}$ ) or $10 \%$ tryptic soy broth (TSB) at $28^{\circ} \mathrm{C}$. A wild-type strain of $F$. graminearum, PH-1 (NRRL 31084), originally isolated from corn in Michigan, U.S.A., was grown at $25^{\circ} \mathrm{C}$ on potato dextrose agar (PDA) medium ( $200 \mathrm{~g}$ of potato dextrose, $20 \mathrm{~g}$ of glucose, and $15 \mathrm{~g}$ of agar in 1 liter of distilled water) for 3 days or yeast extract-peptone-dextrose (YEPD) medium (10 $\mathrm{g}$ of peptone, $3 \mathrm{~g}$ of yeast extract, and $20 \mathrm{of} \mathrm{g}$ 
glucose in 1 liter of distilled water) for 1 day. For conidiation assays, $F$. graminearum $\mathrm{PH}-1$ was inoculated in carboxymethylcellulose (CMC) medium (15 g of sodium carboxymethylcellulose, $1 \mathrm{~g}$ of yeast extract, $1 \mathrm{~g}$ of $\mathrm{NH}_{4} \mathrm{NO}_{3}, 1 \mathrm{~g}$ of $\mathrm{KH}_{2} \mathrm{PO}_{4}$, and $0.5 \mathrm{~g}$ of $\mathrm{MgSO}_{4} \cdot 7 \mathrm{H}_{2} \mathrm{O}$ in 1 liter of distilled water) at $28^{\circ} \mathrm{C}$ for 4 days.

HSAF preparation. We extracted HSAF using methods previously described by Yu et al. (2007) and Zhao et al. (2017). L. enzymogenes strain $\mathrm{OH} 11$ was inoculated into LB medium and incubated at $28^{\circ} \mathrm{C}$ with shaking at $200 \mathrm{rpm}$ until the $\mathrm{OD}_{600}$ reached 1.0. The OH11 cultures were then transferred into $10 \%$ TSB (1:100; vol/ vol) and were incubated at $28^{\circ} \mathrm{C}$ in a rotary shaker at $220 \mathrm{rpm}$ for $24 \mathrm{~h}$. After incubation, bacterial cultures were centrifuged $\left(10,000 \times g\right.$ at $4^{\circ} \mathrm{C}$ for $\left.20 \mathrm{~min}\right)$, and the supernatant was collected. To extract HSAF, an equal volume of ethyl acetate was added to the supernatant, which was acidified with $37 \%$ hydrochloric acid $(0.4 \%[\mathrm{v} / \mathrm{v}])$. The mixture was fully shaken in a rotary shaker at $180 \mathrm{rpm}$ for $1 \mathrm{~h}$, and the ethyl acetate was evaporated in a rotary evaporator. Finally, the remaining residues containing HSAF were fully dissolved in $100 \%$ methanol and purified by highperformance liquid chromatography to obtain HSAF of over $90 \%$ purity.

In vitro effects of HSAF on mycelial growth and morphology. To evaluate the antifungal activity, the effects of different concentrations of HSAF against $F$. graminearum were determined. HSAF was diluted into gradient solutions with methanol, and $50 \mu \mathrm{l}$ of each solution was added into $10 \mathrm{ml}$ of PDA medium to yield final concentrations of $2,4,6,8$, and $10 \mu \mathrm{g} / \mathrm{ml}$. The same volume of methanol was added as a control. A 4-mm mycelial plug was cut from the edge of a fresh $F$. graminearum colony and placed in the center of the HSAF-amended plates. The plates were incubated at $28^{\circ} \mathrm{C}$ for 3 days. There were three replicates in the experiment, and the experiment was repeated three times. The formula for calculating the percent inhibition was as follows:

$$
\text { inhibition }(\%)=\left(1-T_{d} / C_{d}\right) \times 100
$$

where $T_{\mathrm{d}}$ represents the diameter of the growth zone in the HSAF treatment plate $(\mathrm{mm})$ and $C_{\mathrm{d}}$ was the diameter of mycelium in the control plate $(\mathrm{mm})$. The $\mathrm{EC}_{50}$ values (the concentration of inhibiting $50 \%$ of mycelial growth) were calculated using probit-log analysis.

To investigate the effect of HSAF on mycelial morphology, $F$. graminearum was incubated on YEPD medium with $0,2,4,6,8$, and $10 \mu \mathrm{g} / \mathrm{ml}$ concentrations of $\mathrm{HSAF}$ at $28^{\circ} \mathrm{C}$ on a shaker plate at $220 \mathrm{rpm}$ for $24 \mathrm{~h}$, and the mycelium was subsequently transferred onto a glass slide. The morphology of mycelia was examined using the DIC mode of an OLYMPUS-IX71 microscope (Tokyo, Japan) at $40 \times$ magnification.

Conidial germination and conidiation assay. The inhibitory activity of HSAF on conidial germination and germling elongation of $F$. graminearum was evaluated by microscopic observation. HSAF was dissolved in methanol and diluted into serial concentrations. Different concentrations of HSAF solutions prepared at a volume of $5 \mu \mathrm{l}$ were added into conidial suspension $\left(1 \times 10^{5}\right.$ conidia/ml $)$ of $F$. graminearum. Next, $500 \mu \mathrm{l}$ of conidial suspension containing 0.2 to $2 \mu \mathrm{g} / \mathrm{ml}$ of HSAF was incubated at $28^{\circ} \mathrm{C}$ for $2,4,6,8$, and $10 \mathrm{~h}$, and a conidial suspension containing a corresponding volume of methanol used as the control was incubated 2, 4, 6, 8, and $10 \mathrm{~h}$. The experiments were repeated three times. Germination and conidial morphology of each treatment were examined by microscopy using the methods described above.

For the conidiation assay, five mycelial plugs ( $4 \mathrm{~mm}$ in diameter) from the edge of the 3-day-old colony were inoculated into CMC medium containing 0.2 to $10 \mu \mathrm{g} / \mathrm{ml}$ of HSAF. Three replicates of CMC medium containing each concentration of HSAF were performed. After incubation at $28^{\circ} \mathrm{C}$ in a rotary shaker at $180 \mathrm{rpm}$ for 4 days, the number of conidia in each treatment group was determined using a hemocytometer and microscope (OLYMPUS-IX71) at 40× magnification.

Transmission electron microscopy (TEM) observation. Five 4-mm mycelial plugs from the edge of a 3-day-old colony were inoculated on YEPD medium with or without $5 \mu \mathrm{g} / \mathrm{ml}$ of HSAF and incubated at $28^{\circ} \mathrm{C}$ and $180 \mathrm{rpm}$ for $24 \mathrm{~h}$. Mycelial samples for each treatment were collected and fixed with $2 \%$ glutaraldehyde in $0.1 \mathrm{M}$, pH 7.0 sodium phosphate buffer (SPB) overnight at $4^{\circ} \mathrm{C}$. After fixation, the samples were thoroughly rinsed with $\mathrm{SPB}(0.1 \mathrm{M}, \mathrm{pH}$ 7.0) three times and then transferred into $1 \%(\mathrm{~m} / \mathrm{v})$ osmium tetroxide in SPB for $2 \mathrm{~h}$. Subsequently, the mycelia were rinsed with SPB three additional times. After that step, the mycelial samples were dehydrated in serial ethanol solutions (30, 50, 70, 80, 90, and 95\%) and polymerized overnight with Lowicryl K4M hypothermy embedding medium. Blocks were cut into 70-nm slices with an ultramicrotome (LEICA EM UC7) and stained for 5 min with lead citrate and uranyl acetate saturated solution. Finally, the samples were observed with a Hitachi H-7650 TEM.

Field trials. The field trials were conducted in Nanjing, Jiangsu province, China. The experiments were performed as a randomized complete block design with 1-m separation between plots. In each experiment, there were four replicated plots $(4 \times 6 \mathrm{~m})$ per treatment. The Chinese common wheat cultivar Yangmai 158, which is F. graminearum susceptible, was planted to test the efficacy of HSAF. Carbendazim, which is a widely used fungicide in China to control wheat FHB, was used as the positive control, and the application of water was the negative control. HSAF was dissolved in methanol, and the solution was added to $0.1 \%$ Tween 80 aqueous solution to obtain final concentrations of 10,20, and $40 \mu \mathrm{g} / \mathrm{ml}$. At anthesis (Feekes stage 10.5.1), wheat spikes were sprayed with different concentrations of HSAF $\left(1,000 \mathrm{ml} / \mathrm{hm}^{2}\right)$, carbendazim ( $50 \%$ wettable powder; Jiangsu Lanfeng Biochemical Co., $638 \mathrm{~g}$ of active ingredient $/ \mathrm{hm}^{2}$ ), or sterile distilled water. The treatment sprays were applied with a heavy-duty Jacto HD400 backpack sprayer (Agrolex, Singapore) with a flow rate of $710 \mathrm{ml} / \mathrm{min}$. After 7 days, all treatments were performed for the second time. The experimental site was naturally infected. After 2 weeks of the final treatments, wheat heads were collected from five sampling locations in each field plot, and 100 heads of wheat were collected at each sampling location. Finally, the disease incidence (percentage of diseased heads), disease index (DI), and control efficacy were calculated (Hu et al. 2014). DI in wheat heads was assessed with five evaluation classes according to the percentage of wheat head surface showing FHB symptoms $(0,0 \% ; 1,1$ to $25 \% ; 2,26$ to $50 \% ; 3,51$ to $75 \%$; and $4,>75 \%$ ). DI of each plot was calculated using the following formula: $\left[\left(\sum\right.\right.$ number of wheat heads in each class $\times$ class number $) /$ (total number of wheat heads $\times 4$ ) $] \times 100$. The control efficacy of each treatment against FHB in the field was determined by applying the following formula: [(DI of the water control - DI of the treatment)/DI of the water control] $\times 100 \%$. The data of disease incidence, DI, and control efficacy were analyzed with variance analysis by Tukey's test at $\alpha=0.05$ to determine whether the fungicides had a significant effect on controlling FHB.

Statistical analysis. Data were expressed as the mean \pm standard error from three or four replicates per treatment. Differences among different treatments were determined by one-way analysis of variance with Tukey's test at the 0.05 level using SPSS version 25.0.

\section{Results}

In vitro effect on mycelial growth, conidial germination, and conidiation of $\boldsymbol{F}$. graminearum. The antifungal activity against $F$. graminearum of different concentrations of HSAF was investigated.

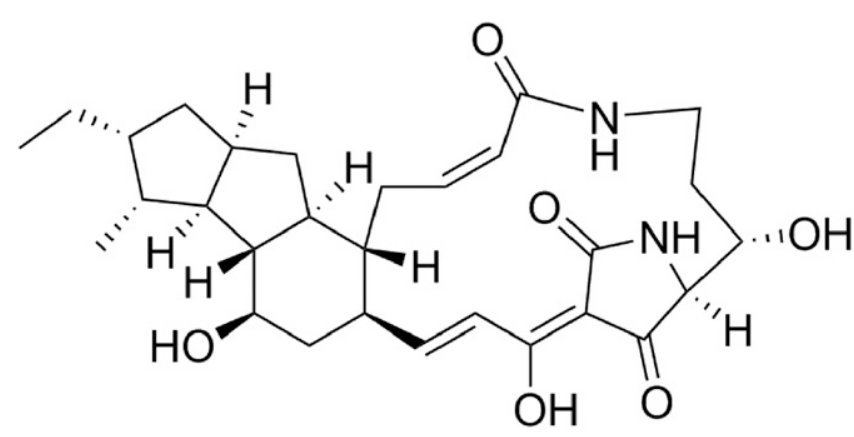

Fig. 1. Chemical structure of heat-stable antifungal factor. 
A
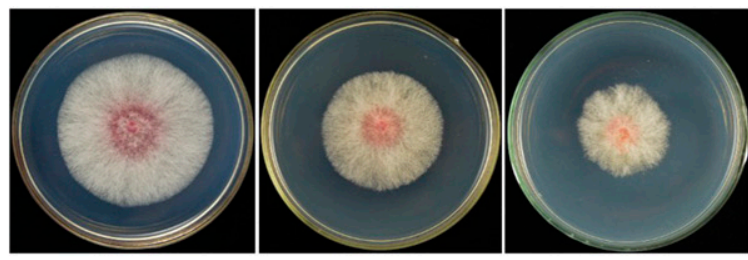

Control

$2 \mu \mathrm{g} / \mathrm{mL}$

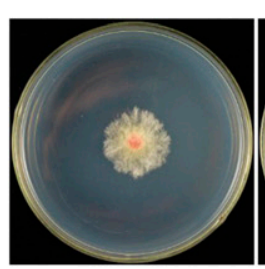

$6 \mu \mathrm{g} / \mathrm{mL}$

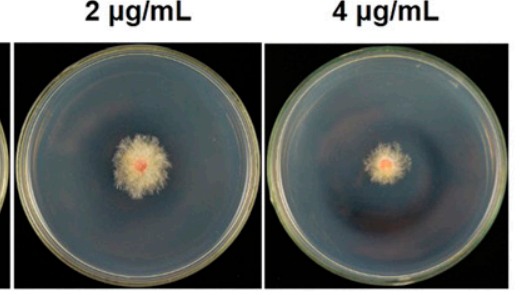

$10 \mu \mathrm{g} / \mathrm{mL}$

B

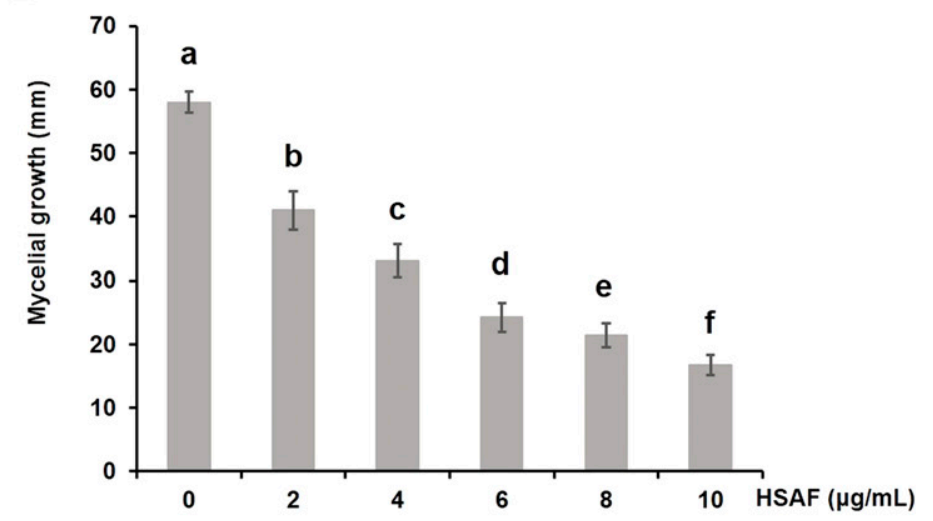

Fig. 2. Inhibitory effect of heat-stable antifungal factor (HSAF) on mycelial growth of Fusarium graminearum. A, Dose-dependent inhibition of HSAF on mycelial growth. B, Diameter of the hyphae in the presence of HSAF, corresponding to A. Different letters indicate statistically significant differences according to Tukey's test $(\alpha=0.05)$.

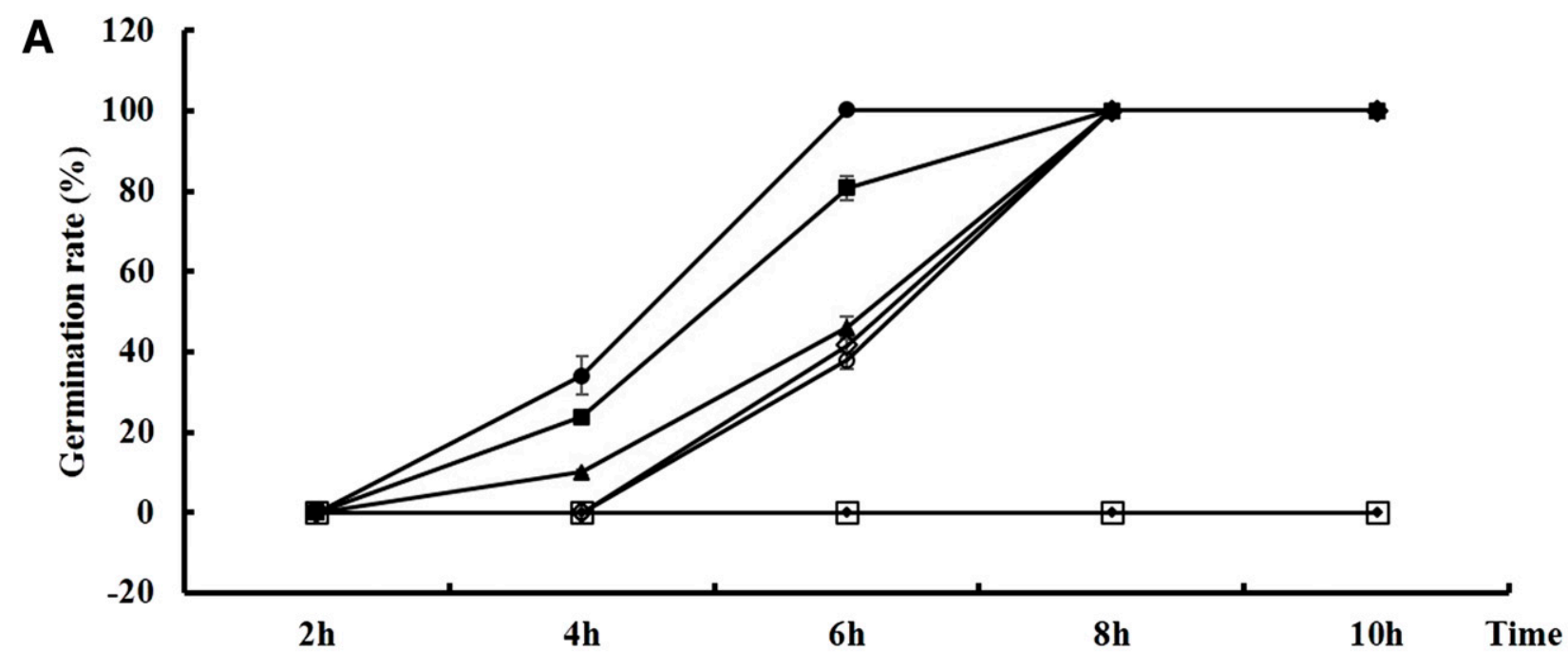

$\rightarrow$ Control $\rightarrow-0.2 \mu \mathrm{g} / \mathrm{mL} \rightarrow 0.4 \mu \mathrm{g} / \mathrm{mL} \multimap-0.6 \mu \mathrm{g} / \mathrm{mL} \multimap-0.8 \mu \mathrm{g} / \mathrm{mL} \rightarrow 1 \mu \mathrm{g} / \mathrm{mL} \rightarrow-2 \mu \mathrm{g} / \mathrm{mL}$

B

$2 \mathrm{~h}$

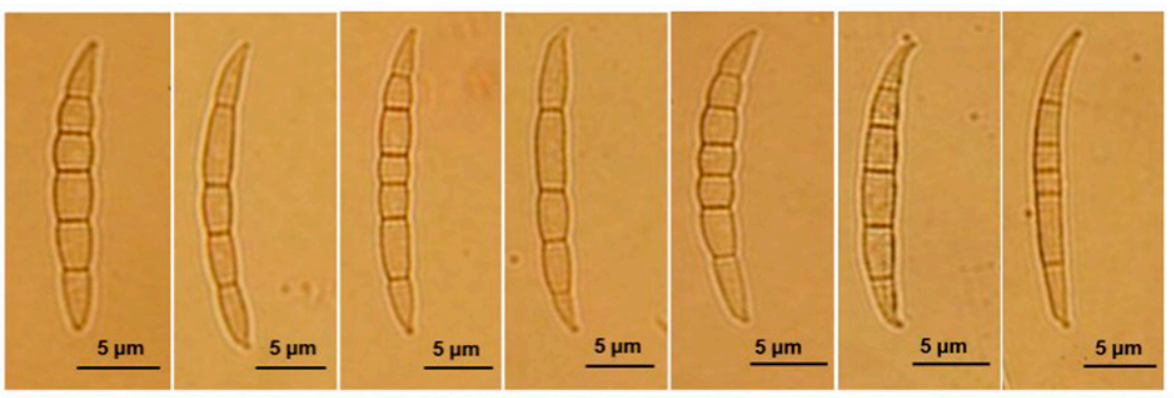

$8 \mathrm{~h}$

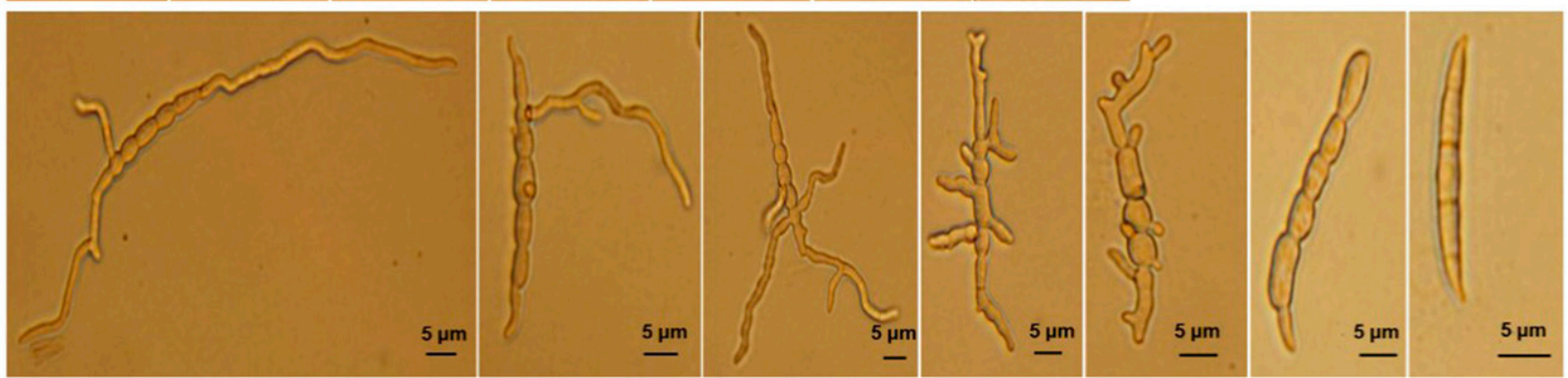

Fig. 3. Inhibitory activity of heat-stable antifungal factor (HSAF) on conidial germination and germling elongation of Fusarium graminearum. A, Effect of HSAF on the percentage of conidial germination. B, Abnormal morphology of germlings after HSAF treatment (from left to right: control, 0.2, 0.4, 0.6, 0.8, 1, and $2 \mu \mathrm{g} / \mathrm{ml}$ of HSAF). 
The results showed that the colony diameter of $F$. graminearum decreased significantly with HSAF treatment compared with the negative control. HSAF possessed dose-dependent activity against $F$. graminearum mycelial growth with an $\mathrm{EC}_{50}$ value of $4.1 \mu \mathrm{g} / \mathrm{ml}$ $(Y=1.7079 X+3.9597, R=0.9917)$ (Fig. 2).

HSAF inhibited conidial germination of $F$. graminearum. Conidia did not start to germinate when incubated at $28^{\circ} \mathrm{C}$ for $2 \mathrm{~h}$ in the assay of the control and HSAF treatment. The control conidia germinated completely after incubation at $28^{\circ} \mathrm{C}$ for $6 \mathrm{~h}$. Germination was inhibited and delayed in the presence of $0.2,0.4,0.6$, or $0.8 \mu \mathrm{g} / \mathrm{ml}$ of HSAF, and germination of $100 \%$ of conidia happened after $8 \mathrm{~h}$. Moreover, application of 1 or $2 \mu \mathrm{g} / \mathrm{ml}$ of HSAF completely prevented conidial germination (Fig. 3A). HSAF inhibited the elongation of germlings and resulted in more germination spots and germ tube branching (Fig. 3B).

Conidiation was inhibited in the HSAF treatment, which showed that the number of conidia was significantly decreased in the presence of $0.2 \mu \mathrm{g} / \mathrm{ml}$ and higher concentrations of HSAF. When

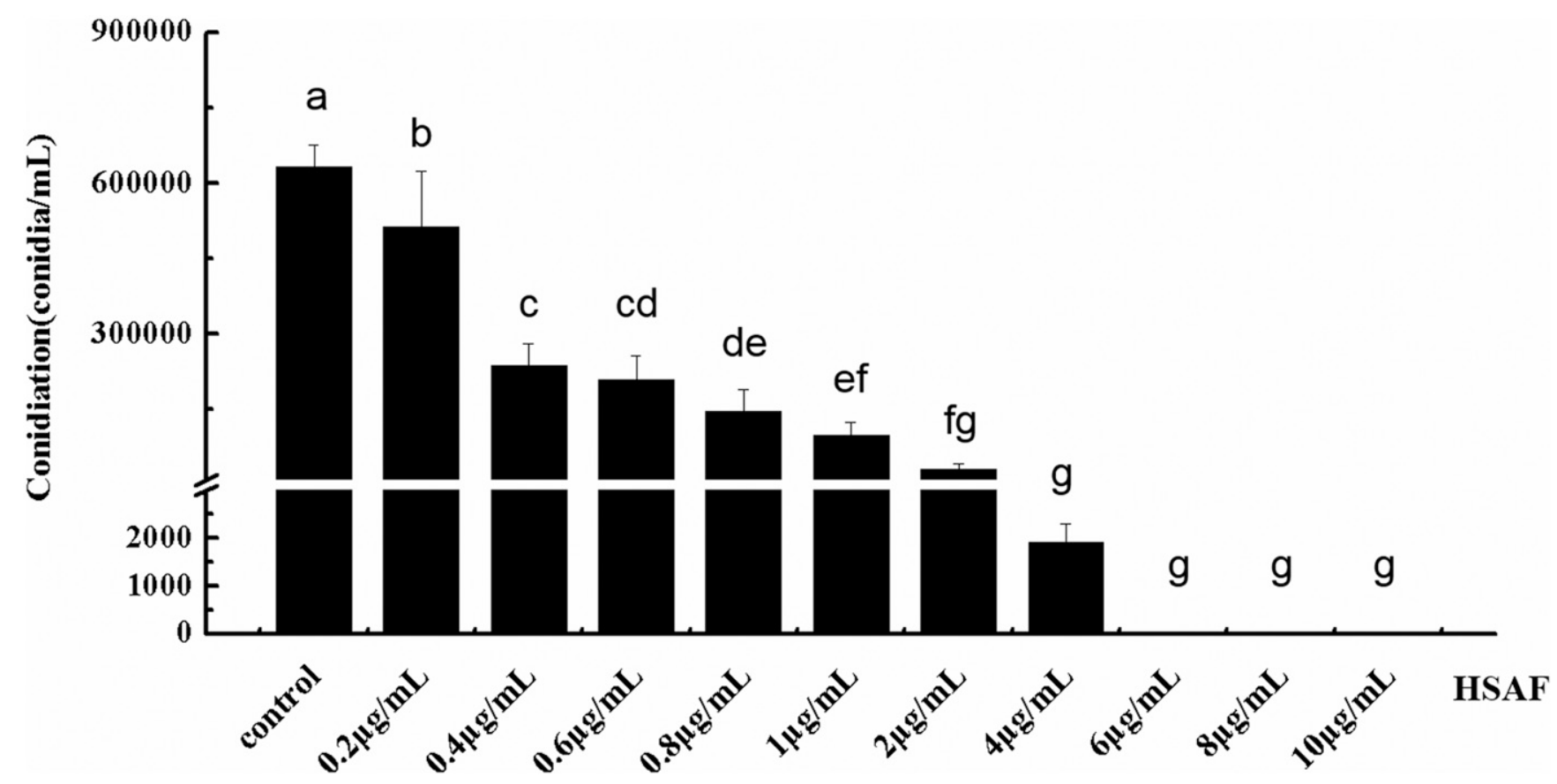

Fig. 4. Conidial production on carboxymethylcellulose medium with different concentrations of heat-stable antifungal factor (HSAF). Each value represents the means of three independent experiments \pm standard deviation. Different letters indicate statistically significant differences according to Tukey's test $(\alpha=0.05)$.
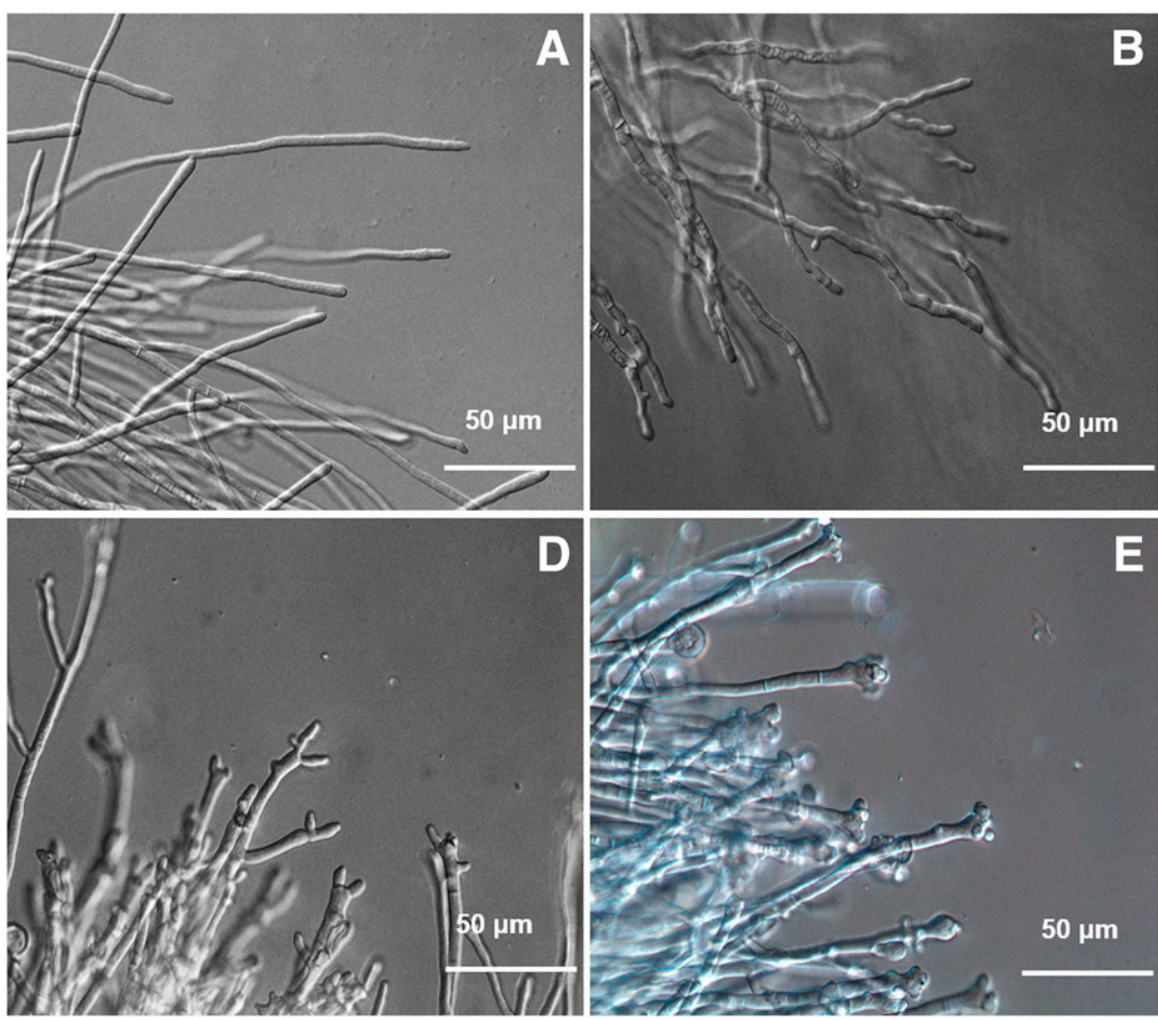

E

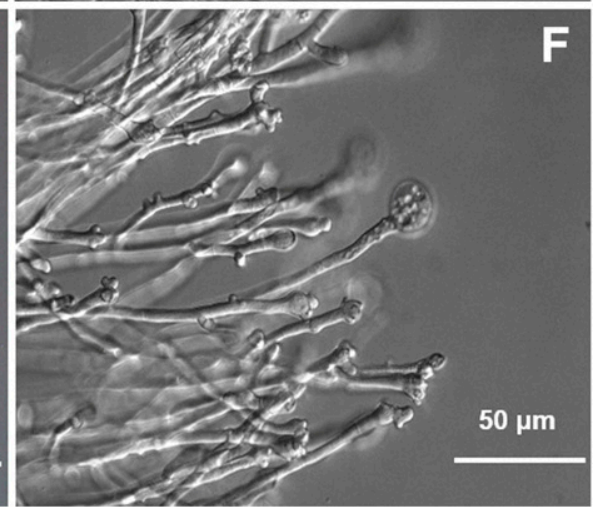

Fig. 5. Changes in the hyphal morphology of Fusarium graminearum with heat-stable antifungal factor (HSAF): A, control; B, $2 \mu \mathrm{g} / \mathrm{ml}$ of HSAF; C, $4 \mu \mathrm{g} / \mathrm{ml}$ of HSAF; D, $6 \mu \mathrm{g} / \mathrm{ml}$ of HSAF; $\mathrm{E}, 8 \mu \mathrm{g} / \mathrm{ml}$ of HSAF; and F, $10 \mu \mathrm{g} / \mathrm{ml}$ of HSAF. 
$6 \mu \mathrm{g} / \mathrm{ml}$ of HSAF was applied, the production of conidia was completely inhibited (Fig. 4).

Changes in hyphal morphology and ultrastructure of $F$. graminearum. $F$. graminearum mycelia without HSAF treatment (control) displayed normal morphology with linear, regular, and smooth hyphae (Fig. 5A). In the presence of 2 and $4 \mu \mathrm{g} / \mathrm{ml}$ of HSAF, the hyphae were distorted, and $6 \mu \mathrm{g} / \mathrm{ml}$ of $\mathrm{HSAF}$ treatment resulted in apex branching (Fig. 5B, C, and D). With 8 and $10 \mu \mathrm{g} / \mathrm{ml}$ of HSAF treatment, the apices of hypha showed multiple ramifications and swelling (Fig. 5E and F).

TEM observation demonstrated that the cell wall and plasma membranes of untreated hyphae were normal and had a uniform organization (Fig. 6A and B). By contrast, treatment with HSAF (5 $\mu \mathrm{g} / \mathrm{ml}$ ) resulted in depolarized hyphal growth and plasmolysis, as well as cell wall thickening (Fig. 6C and D).

Efficacy of HSAF for reducing FHB in wheat. After treatment with different concentrations of HSAF and two control agents, plots were rated for the disease incidence, DI, and control efficacy. All HSAF treatments significantly reduced the disease incidence and DI compared with the water treatment, especially at higher HSAF concentration. The application of 20 and $40 \mu \mathrm{g} / \mathrm{ml}$ of HSAF was equal to the $50 \%$ carbendazim treatment in decreasing disease incidence and DI. However, $10 \mu \mathrm{g} / \mathrm{ml}$ of HSAF was not as effective as $50 \%$ carbendazim in reducing disease incidence and DI. The control efficacy of $10 \mu \mathrm{g} / \mathrm{ml}$ of HSAF, $20 \mu \mathrm{g} / \mathrm{ml}$ of HSAF, $40 \mu \mathrm{g} / \mathrm{ml}$ of $\mathrm{HSAF}$, and $50 \%$ carbendazim were $63.32,74.58,80.32$, and $74.02 \%$, respectively. The results indicated that $40 \mu \mathrm{g} / \mathrm{ml}$ of HSAF significantly improved control efficacy against FHB compared with the 50\% carbendazim. There was no significant difference in control effect between $20 \mu \mathrm{g} / \mathrm{ml}$ of HSAF and $50 \%$ carbendazim, but the effectiveness of $10 \mu \mathrm{g} / \mathrm{ml}$ of HSAF was lower than that of $50 \%$ carbendazim (Table 1).
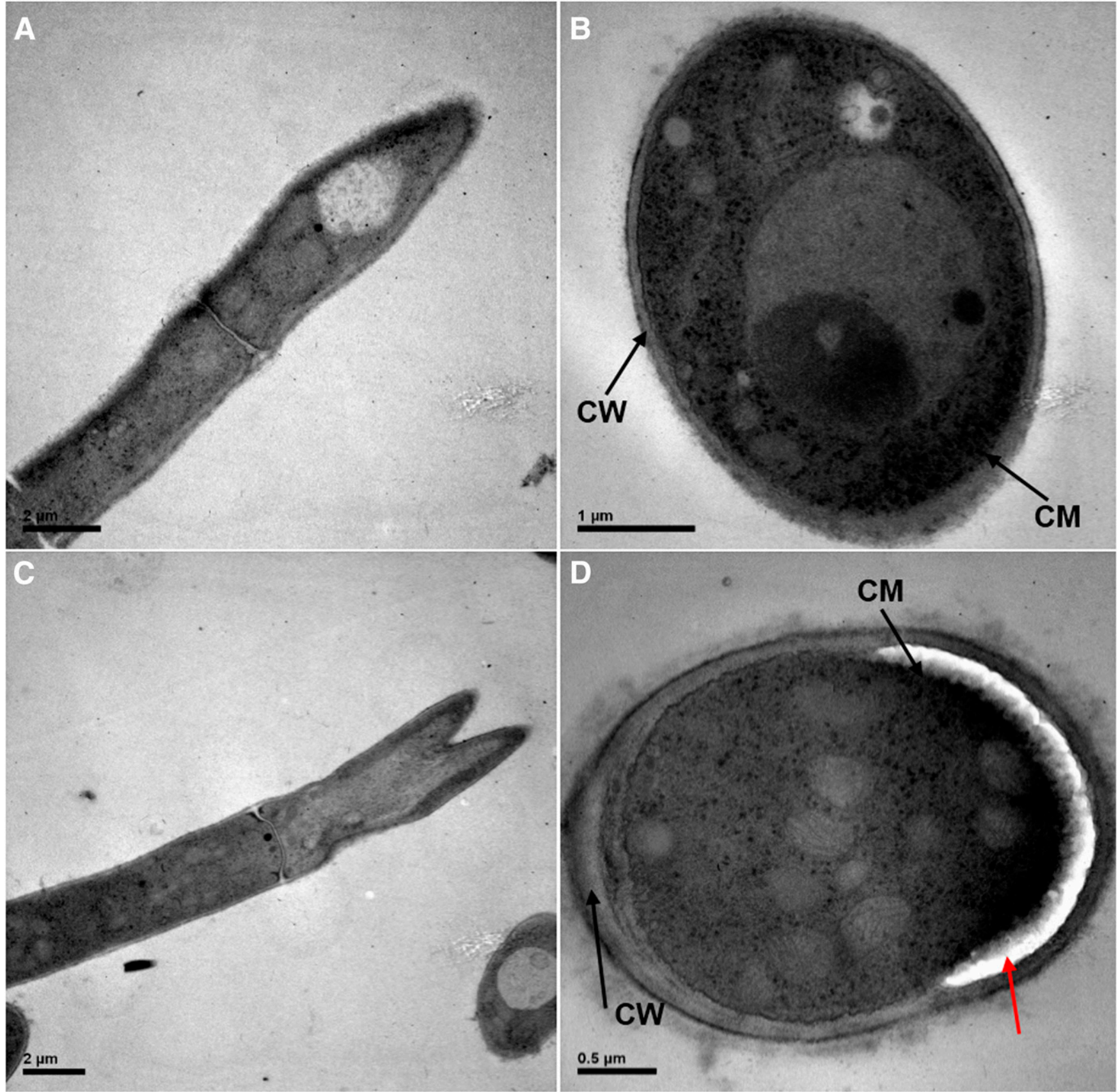

Fig. 6. Transmission electron micrographs for the hyphae of Fusarium graminearum with or without heat-stable antifungal factor (HSAF). A and B, Control; C and D, $5 \mu \mathrm{g} / \mathrm{m}$ of HSAF. A and C show a longitudinal section through the hyphae, and B and D show a tangential section through the hyphae. $\mathrm{CM}=\mathrm{cell}$ membrane, and $\mathrm{CW}=\mathrm{cell}$ wall. The arrow at the bottom right in $\mathrm{D}$ indicates plasmolysis. 
Table 1. Evaluation of heat-stable antifungal factor (HSAF) for control of Fusarium head blight (FHB) in field experiments in Nanjing on Fusarium graminearum-susceptible wheat cultivar Yangmai $158^{\mathrm{w}}$

\begin{tabular}{|c|c|c|c|}
\hline Treatment & $\begin{array}{c}\text { Disease } \\
\text { incidence }(\%)^{x}\end{array}$ & $\begin{array}{l}\text { Disease } \\
\text { index }^{y}\end{array}$ & $\begin{array}{c}\text { Control } \\
\text { efficacy }(\%)^{z}\end{array}$ \\
\hline Water & $23.30 \mathrm{a}$ & $12.64 \mathrm{a}$ & - \\
\hline $50 \%$ carbendazim & $8.90 \mathrm{c}$ & $3.29 \mathrm{c}$ & $74.02 \mathrm{~b}$ \\
\hline $10 \mu \mathrm{g} / \mathrm{ml}$ of $\mathrm{HSAF}$ & $12.20 \mathrm{~b}$ & $4.65 \mathrm{~b}$ & $63.23 \mathrm{c}$ \\
\hline $20 \mu \mathrm{g} / \mathrm{ml}$ of $\mathrm{HSAF}$ & $8.90 \mathrm{c}$ & $3.21 \mathrm{c}$ & $74.58 \mathrm{~b}$ \\
\hline $40 \mu \mathrm{g} / \mathrm{ml}$ of $\mathrm{HSAF}$ & $6.70 \mathrm{c}$ & $2.49 \mathrm{c}$ & $80.32 \mathrm{a}$ \\
\hline
\end{tabular}

${ }^{w}$ Within columns, means followed by different letters differ significantly (Tukey's test, $\alpha=0.05$ ).

$x$ Disease incidence (\%) represents the percentage of diseased heads.

y Disease index was assessed with five evaluation classes according to the percentage of wheat head surface showing FHB symptoms.

z Control efficacy (\%) was calculated from disease index.

\section{Discussion}

FHB is a highly destructive disease of wheat and barley, causing major yield and quality reductions across the world. Contamination of food and feeds with the mycotoxin DON causes a health risk to both humans and animals. Fungicide application is one of the strategies available for management of FHB and DON. However, because DMI and MBC fungicides have been used extensively and widely, resistant Fusarium isolates have been discovered in several countries (Becher et al. 2010; Liu et al. 2010; Spolti et al. 2014; Talas and McDonald 2015; Yin et al. 2009). For instance, JS399-19 (2cyano-3-amino-3-phenylancryic acetate, phenamacril) was a novel and promising cyanoacrylate fungicide developed in China to manage FHB. JS399-19 exhibited specific activity against fungal plant pathogens of the genus Fusarium by strongly inhibiting mycelial growth (Li et al. 2008). The fungicide exhibited excellent efficacy in controlling FHB in field trials by targeting myosin I of $F$. graminearum (Zhang et al. 2015). However, a major gene controlled the resistance to JS399-19 in $F$. graminearum, which makes resistance appear quicker under high selection pressure of the fungicide (Chen et al. 2009). F. graminearum isolates resistant to JS399-19 were quickly found because this fungicide was extensively used in China (Chen and Zhou 2009). The discovery of resistant strains indicates a high possibility for fungicide resistance development and brings a new challenge in the management of FHB and DON using chemical methods. Clearly, these situations underscore the need for developing novel chemicals to combat FHB, but with modes of action different from that of presently used fungicides.

Our results suggested that HSAF strongly suppressed mycelial growth, conidiation, and conidial germination of $F$. graminearum. Ascospores, macroconidia, chlamydospores, and mycelium fragments of $F$. graminearum all can be inoculum for FHB infection. $F$. graminearum survives in soil or crop debris in the form of asexual macroconidia and starts new infection cycles in the spring (Bai and Shaner 2004). The study indicated that HSAF not only could affect infection on wheat heads by inhibiting mycelium growth and conidial germination but also might translate to reducing production of macroconidia in crop debris. In addition to the inhibitory activity, HSAF also led to the malformation of mycelia for $F$. graminearum, such as mycelial curving, swelling, and branching. We discovered plasmolysis in the hyphal cell, which was considered to be the result of intracellular osmotic pressure changes. The result indicated that HSAF affected the permeability of the cytomembrane. We observed that HSAF caused depolarized hyphal growth and cell wall thickening of $F$. graminearum. A previous study suggested that HSAF-induced depolarized hyphal growth and cell wall thickening are related to sphingolipid synthesis in A. nidulans (Li et al. 2006, 2009). However, the molecular and cellular mechanisms of HSAF against fungi are still not well understood. DMI fungicides disrupt the cell membrane by obstructing the biosynthesis of sterol (Odds et al. 2003). MBC fungicides damage microtubules by interacting with $\beta$-tubulin, of which $\beta 1$-tubulin is preferred to $\beta 2$-tubulin (Zhou et al. 2016). The mode of action of HSAF is speculated to be different from the existing fungicides for FHB but needs further study.

The in vivo activity of HSAF against $F$. graminearum has never been reported. In this study, we conducted field experiments, which indicated that the control efficacy of HSAF was dose dependent. Application of $40 \mu \mathrm{g} / \mathrm{ml}$ of HSAF increased control efficacy significantly compared with $50 \%$ carbendazim but showed similar disease incidence and DI. Therefore, we are unable to conclude that $40 \mu \mathrm{g} / \mathrm{ml}$ of HSAF exhibited better effects on FHB control than $50 \%$ carbendazim. The control efficacy of HSAF against FHB in the field needs more exploration, including the determination of an effective concentration, formulation, spray time, and so on. Fungicides developed for FHB control should reduce the level of disease in the field and decrease the accumulation of DON. However, the effect of HSAF on DON concentration has not been investigated.

Strategies used for managing FHB and mycotoxins include resistant cultivars, biological control, crop rotation, tillage, fungicide applications, and disease forecasting. Integrating two or more management strategies is a more effective approach to control FHB and mycotoxins (Shah et al. 2018). Although the use of biological control agents has been reported effective in the laboratory and greenhouse, their commercialization is still in slow progress. Two fungicides, pydiflumetofen and fludioxonil, which were developed by Syngenta as FHB management options in the succinate dehydrogenase inhibitor class of fungicides, have been screened and evaluated for their FHB efficacy and fungicidal activity recently (Hou et al. 2017; Qiu et al. 2018) but have yet to be widely adopted commercially. The in vitro assay and field trials of HSAF showed its strong activity against $F$. graminearum, which provided insight into the development of novel fungicides for control of FHB on wheat. For the commercialization of HSAF, it will be further evaluated as a fungicide or in combination with other integrated management tools including current fungicides against FHB. Its efficacy against other Fusarium species, manufacturing method, physical and chemical properties, formulation, and safety for mammals and the environment will also be studied.

\section{Literature Cited}

Bai, G., and Shaner, G. 2004. Management and resistance in wheat and barley to Fusarium head blight. Annu. Rev. Phytopathol. 42:135-161.

Becher, R., Hettwer, U., Karlovsky, P., Deising, H. B., and Wirsel, S. G. 2010. Adaptation of Fusarium graminearum to tebuconazole yielded descendants diverging for levels of fitness, fungicide resistance, virulence, and mycotoxin production. Phytopathology 100:444-453.

Chen, Y., Chen, C. J., Zhou, M. G., Wang, J. X., and Zhang, W. Z. 2009. Monogenic resistance to a new fungicide, JS399-19, in Gibberella zeae. Plant Pathol. 58:565-570.

Chen, Y., and Zhou, M. G. 2009. Characterization of Fusarium graminearum isolates resistant to both carbendazim and a new fungicide JS399-19. Phytopathology 99:441-446.

Dean, R., Van Kan, J. A. L., Pretorius, Z. A., Hammond-Kosack, K. E., Pietro, A. D., Spanu, P. D., Rudd, J. J., Dickman, M., Kahmann, R., Ellis, J., and Foster, G. D. 2012. The Top 10 fungal pathogens in molecular plant pathology. Mol. Plant Pathol. 13:414-430.

Ding, Y. J., Li, Z. J., Li, Y. Y., Lu, C. H., Wang, H. X., Shen, Y. M., and Du, L. C. 2016. HSAF-induced antifungal effects in Candida albicans through ROSmediated apoptosis. RSC Advances 6:30895-30904.

Dweba, C. C., Figlan, S., Shimelis, H. A., Motaung, T. E., Sydenham, S., Mwadzingeni, L., and Tsilo, T. J. 2017. Fusarium head blight of wheat: Pathogenesis and control strategies. Crop Prot. 91:114-122.

EFSA Panel on Contaminants in the Food Chain, Knutsen, H. K., Alexander, J., Barregård, L., Bignami, M., Brüschweiler, B., Ceccatelli, S., Cottrill, B., Dinovi, M., Grasl-Kraupp, B., Hogstrand, C., Hoogenboom, L. R., Nebbia, C. S., Oswald, I. P., Petersen, A., Rose, M., Roudot, A. C., Schwerdtle, T., Vleminckx, C., Vollmer, G., Wallace, H., De Saeger, S., Eriksen, G. S., Farmer, P., Fremy, J. M., Gong, Y. Y., Meyer, K., Naegeli, H., ParentMassin, D., Rietjens, I., van Egmond, H., Altieri, A., Eskola, M., Gergelova, P., Bordajandi, R. L., Benkova, B., Dörr, B., Gkrillas, A., Gustavsson, N., van Manen, M., and Edler, L. 2017. Scientific opinion on the risks to human and animal health related to the presence of deoxynivalenol and its acetylated and modified forms in food and feed. EFSA J. 15:4718.

Folman, L. B., De Klein, M. J. E. M., Postma, J., and van Veen, J. A. 2004 Production of antifungal compounds by Lysobacter enzymogenes isolate 
3.1T8 under different conditions in relation to its efficacy as a biocontrol agent of Pythium aphanidermatum in cucumber. Biol. Control 31:145-154.

Folman, L. B., Postma, J., and van Veen, J. A. 2003. Characterization of Lysobacter enzymogenes (Christensen and Cook 1978) strain 3.1T8, a powerful antagonist of fungal diseases of cucumber. Microbiol. Res. 158: $107-115$.

Hou, Y. P., Mao, X. W., Wang, J. X., Zhan, S. W., and Zhou, M. G. 2017. Sensitivity of Fusarium asiaticum to a novel succinate dehydrogenase inhibitor fungicide pydiflumetofen. Crop Prot. 96:237-244.

Hu, W. Q., Gao, Q. X., Hamada, M. S., Dawood, D. H., Zheng, J. W., Chen, Y., and Ma, Z. H. 2014. Potential of Pseudomonas chlororaphis subsp. aurantiaca strain Pcho10 as a biocontrol agent against Fusarium graminearum. Phytopathology 104:1289-1297.

Jochum, C. C., Osborne, L. E., and Yuen, G. Y. 2006. Fusarium head blight biological control with Lysobacter enzymogenes strain C3. Biol. Control 39: 336-344.

Katika, M. R., Hendriksen, P. J., van Loveren, H., and Peijnenburg, A. A. C. M. 2014. Characterization of the modes of action of deoxynivalenol (DON) in the human Jurkat T-cell line. J. Immunotoxicol. 12:206-216.

Li, H. K., Diao, Y. M., Wang, J. X., Chen, C. J., Ni, J. P., and Zhou, M. G. 2008. JS399-19, a new fungicide against wheat scab. Crop Prot. 27:90-95.

Li, S. J., Calvo, A. M., Du, L. C., Yuen, G. Y., and Harris, S. D. 2009. Induction of cell wall thickening by the antifungal compound dihydromaltophilin disrupts fungal growth and is mediated by sphingolipid biosynthesis. J. Eukaryot. Microbiol. 56:182-187.

Li, S. J., Du, L. C., Yuen, G. Y., and Harris, S. D. 2006. Distinct ceramide synthases regulate polarized growth in the filamentous fungus Aspergillus nidulans. Mol. Biol. Cell 17:1218-1227.

Liu, X., Yin, Y. N., Wu, J. B., Jiang, J. H., and Ma, Z. H. 2010. Identification and characterization of carbendazim resistant isolates of Gibberella zeae. Plant Dis. 94:1137-1142

Lou, L. L., Qian, G. L., Xie, Y. X., Hang, J. L., Chen, H. T., Zaleta-Rivera, K., Li, Y., Shen, Y., Dussault, P. H., Liu, F., and Du, L. 2011. Biosynthesis of HSAF, a tetramic acid-containing macrolactam from Lysobacter enzymogenes. J. Am. Chem. Soc. 133:643-645.

McMullen, M., Bergstrom, G., De Wolf, E., Dill-Macky, R., Hershman, D., Shaner, G., and Van Sanford, D. 2012. A unified effort to fight an enemy of wheat and barley: Fusarium head blight. Plant Dis. 96:1712-1728.

Odds, F. C., Brown, A. J. P., and Gow, N. A. R. 2003. Antifungal agents: Mechanisms of action. Trends Microbiol. 11:272-279.

Pestka, J. J. 2010. Deoxynivalenol: Mechanisms of action, human exposure, and toxicological relevance. Arch. Toxicol. 84:663-679.

Qian, G. L., Hu, B. S., Jing, Y. H., and Liu, F. Q. 2009. Identification and characterization of Lysobacter enzymogenes as a biological control agent against some fungal pathogens. Agric. Sci. China 8:68-75

Qian, G. L., Wang, Y. L., Liu, Y. R., Xu, F. F., He, Y. W., Du, L. C., Venturi, V., Fan, J. Q., Hu, B. S., and Liu, F. Q. 2013. Lysobacter enzymogenes uses two distinct cell-cell signaling systems for differential regulation of secondary-metabolite biosynthesis and colony morphology. Appl. Environ. Microbiol. 79:6604-6616.

Qiu, J. B., Yu, M. Z., Yin, Q., Xu, J. H., and Shi, J. R. 2018. Molecular characterization, fitness, and mycotoxin production of Fusarium asiaticum strains resistant to fludioxonil. Plant Dis. 102:1759-1765

Shah, L., Ali, A., Yahya, M., Zhu, Y., Wang, S., Si, H. H., Rahman, H., and Ma, C. 2018. Integrated control of Fusarium head blight and deoxynivalenol mycotoxin in wheat. Plant Pathol. 67:532-548.

Sobrova, P., Adam, V., Vasatkova, A., Beklova, M., Zeman, L., and Kizek, R. 2010. Deoxynivalenol and its toxicity. Interdiscip. Toxicol. 3:94-99.

Spolti, P., Del Ponte, E. M., Dong, Y., Cummings, J. A., and Bergstrom, G. C. 2014. Triazole sensitivity in a contemporary population of Fusarium graminearum from New York wheat and competitiveness of a tebuconazoleresistant isolate. Plant Dis. 98:607-613.

Su, Z. H., Chen, H. F., Wang, P., Tombosa, S., Du, L. C., Han, Y., Shen, Y. M., Qian, G. L., and Liu, F. Q. 2017. 4-Hydroxybenzoic acid is a diffusible factor that connects metabolic shikimate pathway to the biosynthesis of a unique antifungal metabolite in Lysobacter enzymogenes. Mol. Microbiol. 104 163-178.

Talas, F., and McDonald, B. A. 2015. Significant variation in sensitivity to a DMI fungicide in field populations of Fusarium graminearum. Plant Pathol. 64: 664-670.

Wegulo, S. N., Baenziger, P. S., Nopsa, J. H., Bockus, W. W., and Hallen-Adams, H. 2015. Management of Fusarium head blight of wheat and barley. Crop Prot. 73:100-107.

Xu, G. G., Han, S., Huo, C. M., Chin, K. H., Chou, S. H., Gomelsky, M., Qian, G. L., Liu, F. Q. 2018. Signaling specificity in the c-di-GMP-dependent network regulating antibiotic synthesis in Lysobacter. Nucleic Acids Res. 46: 9276-9288.

Yin, Y. N., Liu, X., Li, B. Q., and Ma, Z. H. 2009. Characterization of sterol demethylation inhibitor-resistant isolates of Fusarium asiaticum and $F$. graminearum collected from wheat in China. Phytopathology 99:487-497.

Yu, F. G., Zaleta-Rivera, K., Zhu, X. C., Huffman, J., Millet, J. C., Steven, D. Harris, S. D., Yuen, G., Li, X. C., and Du, L. C. 2007. Structure and biosynthesis of heat-stable antifungal factor (HSAF), a broad-spectrum antimycotic with a novel mode of action. Antimicrob. Agents Chemother. 51: 64-72.

Zhang, C. Q., Chen, Y., Yin, Y. N., Ji, H. H., Shim, W. B., Hou, Y. P., Zhou, M. G., Li, X. D., and Ma, Z. H. 2015. A small molecule species specifically inhibits Fusarium myosin I. Environ. Microbiol. 17:2735-2746.

Zhang, Z., and Yuen, G. Y. 1999. Biological control of Bipolaris sorokiniana on tall fescue by Stenotrophomonas maltophilia C3. Phytopathology 89:817-822.

Zhao, Y. Y., Qian, G. L., Chen, Y., Du, L. C., and Liu, F. Q. 2017. Transcriptional and antagonistic responses of biocontrol strain Lysobacter enzymogenes $\mathrm{OH} 11$ to the plant pathogenic oomycete Pythium aphanidermatum. Front. Microbiol. 8:1025.

Zhou, Y. J., Zhu, Y. Y., Li, Y. J., Duan, Y. B., Zhang, R. S., and Zhou, M. G. 2016. $\beta 1$ Tubulin rather than $\beta 2$ tubulin is the preferred binding target for carbendazim in Fusarium graminearum. Phytopathology 106:978-985. 